NIST GCR 11-936

\title{
CCR Suitability Analysis
}

Lantana Consulting Group

National Institute of Standards and Technology • U.S. Department of Commerce 


\title{
CCR Suitability Analysis
}

\author{
Prepared for \\ National Institute of Standards and Technology \\ Gaithersburg Md 20899-8202
}

By

Lantana Consulting Group

May 2011

U.S. Department of Commerce

Rebecca M. Blank, Acting Secretary

National Institute of Standards and Technology Patrick D. Gallagher, Under Secretary for Standards and Technology and Director

Certain commercial entities, equipment, or materials may be identified in this document in order to describe an experimental procedure or concept adequately. Such identification is not intended to imply recommendation or endorsement by the National Institute of Standards and Technology, nor is it intended to imply that the entities, materials, or equipment are necessarily the best available for the purpose. 


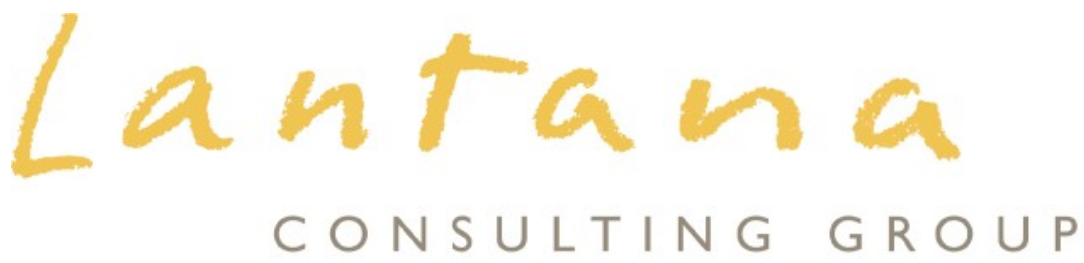

CCR Suitability Analysis

May 2011

Prepared by Lantana Consulting Group

for

National Institute of Standards and Technology

Lantana Consulting Group

Prepared for NIST

ü 2011, all rights reserved
CCR Suitability Analysis May 2011

Page 3 
(C) 2011 Lantana Consulting Group

All rights reserved.

\section{Lantana Consulting Group}

PO Box 177

East Thetford, VT 05043

www.lantanagroup.com

Liora Alschuler

Chief Executive Officer

liora.alschuler@lantanagroup.com

Bob Dolin, MD, FACP

President and Chief Medical Officer

bob.dolin@1antanagroup.com

Rick Geimer

Chief Technology Officer

rick.geimer@lantanagroup.com

Lauren Wood, Ph.D.

Senior Project Manager

lauren.wood@lantanagroup.com

Gaye Dolin, RN, MSN

Senior Nurse Informaticist

gaye.dolin@,lantanagroup.com

Jingdong Li, MD

Chief Architect

jingdong.li@lantanagroup.com

Yan Heras

Senior Medical Informaticist

yan.heras@lantanagroup.com

Bob Yencha

Principal Consultant

bob.yencha@lantanagroup.com

Kate Hamilton

Senior Information Analyst

kate.hamilton@lantanagroup.com

Susan Hardy

Senior Technical Editor

susan.hardy@lantanagroup.com

Lantana Consulting Group

Prepared for NIST

ü 2011, all rights reserved
CCR Suitability Analysis May 2011

Page 4 


\section{Acknowledgments}

This analysis was produced and developed by Lantana Consulting Group for the National Institute of Standards and Technology (NIST ), under contract number SB134110SE0881.

We appreciate the information and insights provided by several healthcare experts who answered our e-mail questionnaire or took part in phone interviews. Those who participated in the Continuity of Care Record (CCR) phone interviews were Anthony LaRocca, Sage Software; Ben Hamlin, National Committee for Quality Assurance (NCQA); David Parker, Evolvent; George Cole, Allscripts; Austin Kreisler, SAIC; Paul Klinker, Harris; Tone Southerland, Greenway; and Steve Waldren, American Academy of Family Physicians (AAFP).

Any mention of commercial products or organizations in this report is for information only; it does not imply recommendation or endorsement by Lantana or NIST.

Lantana Consulting Group

Prepared for NIST

ü 2011, all rights reserved
CCR Suitability Analysis May 2011

\section{Page 5}




\title{
Table of Contents
}

\author{
Executive Summary 6 \\ Introduction 7 \\ CCR Summary of Purpose 7 \\ CCR and Meaningful Use 8 \\ CCR and CCD 9 \\ Stakeholder Interviews 10 \\ CCR Suitability Analysis 12
}

Is the standard based on a stable, well-vetted data model? 12

Does the standard have a clear, robust vocabulary binding syntax? 13

Does the standard support the use of reusable modules, such as templates or data types?13

Does the standard have a well-defined constraint mechanism? 13

Does the standard have a well-defined extensibility mechanism?

Are there unambiguous definitions of what is testable? 14

Are there automated test tools and test suites? 14

Are there reference implementations for the standard? 14

Has the standard been implemented by a range of vendors?

Is there documented existence of errors, including estimates of the severity?

Is there a defined and effective process for handling errors?

17

Do industry associations endorse the standard?

Is the standard used in more than one country?18

Is certification available for developers and architects? 18

CCR Suitability Summary 19

Meaningful Use Analysis $\quad 20$

Meaningful Use: Vocabulary Set

20

Meaningful Use: Core Set 21

Meaningful Use: Menu Set 24

Conclusions 26

References $\quad 28$

Acronyms and Abbreviations 30

Lantana Consulting Group

Prepared for NIST

ü 2011, all rights reserved
CCR Suitability Analysis May 2011

Page 6 


\section{List of Figures}

Figure 1: Meaningful Use and CCR 8

Figure 2: CCR XML smoking status example 1 21

Figure 3: CCR XML smoking status example 2 22

Figure 4: Meaningful-Use compliant CCR XML smoking status example 22

\section{List of Tables}

Table 1: CCR Standard-Specific Interview Questions 10

Table 2: CCR Criteria Matrix $\quad 19$

Table 3: Meaningful Use Vocabulary Set Supported by CCR 20

Table 4: Meaningful Use Core Set Supportable by CCR 23

Table 5: Meaningful Use Menu Set Supportable by CCR 25 


\section{Executive Summary}

This document analyzes the suitability of the ASTM Continuity of Care Record (CCR) specification to support the US Department of Health and Human Services' (HHS) Meaningful Use (MU). It is part of the Healthcare Information Technology (HIT) Standards Analysis Project carried out by Lantana Consulting Group for The National Institute of Standards and Technology (NIST).

We applied the methodology described in the "Healthcare Information Technology Standards: General Suitability Analysis" document, also prepared for NIST. The CCR standard meets some of the required defined suitability criteria. To meet all the criteria, a number of deficiencies should be corrected. Chief among them are the needs for constraint and extensibility mechanisms and for a profile of the CCR standard that meets the functionality requirements of Meaningful Use. 
This document analyzes how the ASTM ${ }^{1}$ Continuity of Care Record (CCR) standard supports the US Department of Health and Human Services' (HHS) Meaningful Use. It is part of the Healthcare Information Technology (HIT) Standards Analysis Project carried out by Lantana Consulting Group for the National Institute of Standards and Technology (NIST). In this project, we assessed the suitability of four standards: CCR, Quality Reporting Data Architecture (QRDA), Continuity of Care Document (CCD), and Health Level Seven (HL7) V2 Biosurveillance. These findings are reported in separate documents.

CCR documents may be prepared, transmitted, and viewed in multiple ways, including email and PDF (portable document format) files. This analysis applies only to structured electronic documents that contain Extensible Markup Language (XML) coding. With XML coding, a CCR may be transmitted and viewed as an element in an HL7 message or as a Clinical Document Architecture (CDA) compliant document. This analysis applies to the non-CDA XML encoding.

\section{CCR Summary of Purpose}

A CCR document is an exchange object between electronic health record (EHR) systems (not a clinical document that should be stored). CCR communicates

... the most relevant administrative, demographic, and clinical information facts about a patient's healthcare, covering one or more healthcare encounters. It provides a means for one healthcare practitioner, system, or setting to aggregate all of the pertinent data about a patient and forward it to another practitioner, system, or setting to support continuity of care."2

The CCR data set includes a summary of the patient's health status (for example problems, medications, and allergies) and basic information about insurance, advance directives, care documentation, and the patient's care plan.

CCR was not designed to be a long-lived document. It is a summary of relevant patient data as determined by the physician based on the expected use of that data. As stated by Peters et al. (2005):

The ASTM CCR is not, however, a 'clinical document' - such as a Clinical Note, Encounter Note, History \& Physical, or Discharge Summary, each of which are medical legal documents, generated and signed by one or more directly responsible clinical authors.

The best way to understand a ASTM CCR is as a collection of data from many clinical documents - documents such as Clinic Notes, H\&Ps, Discharge Summaries, Prescriptions, Orders, Results documents, Operative Reports, Procedure Notes, etc. The ASTM CCR is what physicians or clinical or administrative health care providers generate either on scratch paper, in our heads, or in another document such as an H\&P (History and Physical) or

1 Originally called American Society for Testing Materials

2 ASTM Standard E2369 - 05e1. Standard Specification for Continuity of Care Record (CCR), 2005. http://www.astm.org/Standards/E2369.htm, Section 1.1 of the Abstract.

Lantana Consulting Group CCR Suitability Analysis May 2011

ü 2011, all rights reserved 
Discharge Summary when they 'review' the patient chart or charts. The ASTM CCR is an aggregation of all of the pertinent data from all the documents in the chart(s) and the compilation and parsing of that data into a uniform and easily interpreted format - the CCR. [...]

To reiterate, the ASTM CCR is not a 'clinical document;' the ASTM CCR is an aggregation of clinical and administrative data from multiple documents from multiple disparate sources.

\section{CCR and Meaningful Use}

The primary objective of Stage 1 Meaningful Use is to leverage technology to achieve significant improvements in patient care. The Meaningful Use goals are to: (1) improve quality, efficiency, and safety and reduce health disparities; (2) engage patients and families; (3) improve care coordination; (4) improve population and public health; and (5) ensure adequate privacy and security protections for personal health information. ${ }^{3}$

CCR supports the Meaningful Use goals of improving quality, efficiency, safety, and coordination and of reducing health disparities (the first and third goals listed above). CCR helps transmit automated healthcare information with minimal workflow disruption for practitioners, and allows data to be exchanged between otherwise incompatible EHR systems, although aggregation of that data is not feasible without using a profile.

\section{Figure 1: Meaningful Use and CCR}

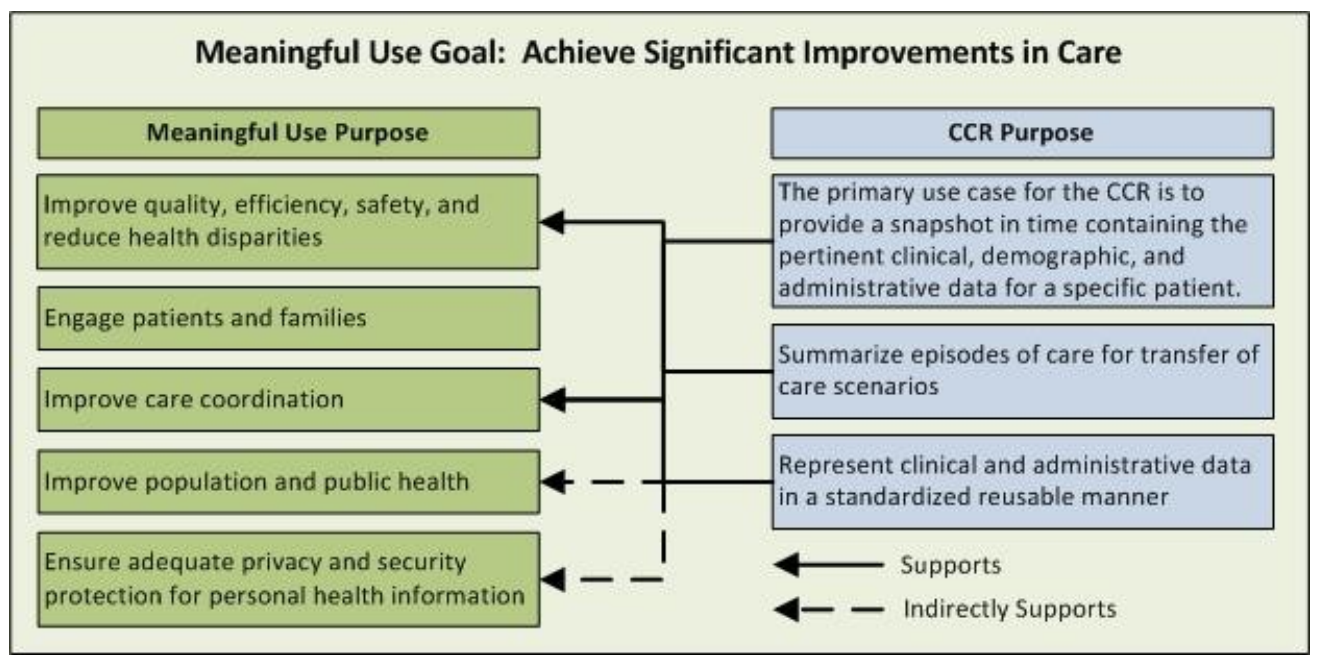

\section{CCR and CCD}

3 Department of Health and Human Services. Medicare and Medicaid Programs; Electronic Health Record Incentive Program; Final Rule - Stage One Meaningful Use Objectives 42 CFR (Code of Federal Regulations) Parts 412, 413, 422 et al. http://edocket.access.gpo.gov/2010/pdf/2010-17207.pdf

\begin{tabular}{|c|c|}
\hline Lantana Consulting Group & CCR Suitability Analysis \\
\hline $\begin{array}{l}\text { Prepared for NIST } \\
\text { ü 2011, all rights reserved }\end{array}$ & Page 10 \\
\hline
\end{tabular}


CCR is closely related to HL7's Continuity of Care Document (CCD). CCD - a collaborative effort between HL7 and ASTM ${ }^{4,5}$-is essentially a CDA implementation of the medical information in a CCR. The major concepts within the two formats are similar and can be mapped accurately and transformed reliably where the variability in each specification is constrained. A general mapping is not feasible.

4 http://www.hl7standards.com/blog/2010/03/10/ccd-and-ccr-the-discussion-continues/ 5 http://projectpophealth.org/glossary.html

\section{Lantana Consulting Group}

Prepared for NIST

ü 2011, all rights reserved
CCR Suitability Analysis Page 11

May 2011 
Stakeholder Interviews

As described in the "Healthcare Information Technology Standards: General Suitability Analysis", also prepared for NIST, we interviewed experts in HIT standards development, quality reporting, and standards implementation to supplement our own experience and knowledge of CCR. The table below lists the questions that guided the discussion on CCR.

We also reviewed material on the web and communicated privately with implementers, members of the CCR design committee, and the ASTM Staff Liaison for Committee E31.

Table 1: CCR Standard-Specific Interview Questions

\begin{tabular}{|c|c|}
\hline Question block ID & Interview Questions \\
\hline [CCR] & $\begin{array}{l}\text { Please briefly describe your experience with CCR to help us understand the } \\
\text { basis for your answers to the following questions. } \\
\text { The primary purpose of CCR is to transmit summary data. How well is CCR } \\
\text { meeting its primary purpose? } \\
\text { Are there errors or ambiguities in CCR that mean it is harder than it should be } \\
\text { to implement and use? Do you have examples? } \\
\text { Consider the primary purpose of CCR: } \\
\text { O What are some measurable criteria that should be assessed to ensure it } \\
\text { is meeting this purpose? } \\
\text { In what ways does it not meet its purpose? } \\
\text { Where is "suitability" or "fitness for purpose" lacking or present in CCR? For } \\
\text { instance, here are some potential areas: } \\
\text { O Narrative interoperability or immediate, accurate rendering in a } \\
\text { receiving system } \\
\text { Data reconciliation } \\
\text { O Data reuse } \\
\text { Third-party aggregation of data (e.g., ability of disparate systems to } \\
\text { Please discuss the one feature about CCR that most supports the Meaningful } \\
\text { Use ultimate goal of achieving significant improvements in health care. }\end{array}$ \\
\hline
\end{tabular}

Senior developers and government-level directors who had some experience with the CCR standard and its implementation provided insight. Most people with CCR experience also had experience with the CCD. Thus, many of their comments should be viewed as comparisons of the two standards.

CCR is generally seen to be relatively easy to understand and implement. It is defined in one document and it was designed to meet one specific use case. It is not modular and there are no related standards using the same model or XML conventions.

6 Lantana Consulting Group. Healthcare Information Technology Standards: General Suitability Analysis, May 2011. Related document prepared for NIST.

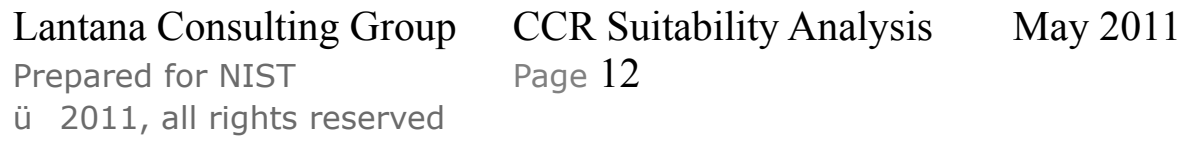


We discussed two issues in some depth. One is that what is rendered to the clinician onscreen is completely up to the receiver of a CCR document. One interviewee thought this allows a system to render information in a consistent format, regardless of its source or the intention of the source clinician. Other interviewees were concerned that this could create incomplete and medically dangerous documents. Some providers use free-form text while others use structured information. Some style sheets show all information, including what is in free-form text, but, in one case, the style sheet worked only when all the structured elements were complete - without all elements, no information was shown.

The other issue was that, although CCR recommends the use of code sets, it also allows free text. 
CCR Suitability Analysis

This section applies the questions defined in the "Healthcare Information Technology Standards: General Suitability Analysis" to CCR

\section{Is the standard based on a stable, well-vetted data model?}

CCR was developed by ASTM International Technical Committee E31 on Healthcare Informatics in Subcommittee 31.25 on Healthcare Data Management, Security, Confidentiality, and Privacy ${ }^{7}$. ASTM is a recognized international standards developing organization (SDO) with a consensusdriven approach. Membership is open to all who can pay the membership fee. This SDO structure typically makes it possible for any interested experts to take part in the development of a standard to ensure that it meets the needs of the community. In this case, ASTM E31 had a large number of healthcare experts working on the design of CCR. As of March 2011, CCR is listed as an ACTIVE standard under the jurisdiction of E31.25 (although the latest version was published in 2005).

CCR has a data model insofar as an XML document with a structure that conforms to a specific schema has a data model. Using the World Wide Web Consortium Document Object Model (W3C DOM), all information units within an XML document can be represented by data objects within a software application. Annex A2.2 of the CCR standard refers to this:

(2) The CCR Document Object is constructed from a set of discrete XML building blocks, which are defined as Data Objects.

(3) The Data Objects are contained within Sections, such as Medications, Immunizations, Problems, and Procedures, in the CCR Document Object.

(4) Each discrete Medication, Immunization, Problem, Procedure represents a discrete data object within the CCR.

The CCR XML object model could be applied to use cases within a restricted area, where such use cases are essentially variations on a theme of CCR. Application to other, more extensive use cases would require significant work to develop a consistent underlying conceptual model, if the resulting standards were to be properly compatible with each other. Such a conceptual model would also make it easier to relate the XML data model to the models required for healthcare IT implementations. The XML schema for CCR can represent some object relationships, but cannot represent all of the constraints required. Other, more formal ways of describing the data model, such as the Unified Modeling Language (UML) ${ }^{8}$ in combination with the Object Constraint Language (OCL), can represent additional relationships and constraints. Even this method, however, does not represent all constraints; the rest must be expressed in natural language.

A number of experts participated in the development of CCR and it went through more than one cycle of ANSI ballot, so the XML data model was well vetted, but it remains limited. It does not have an underlying conceptual model and does not cover all the necessary relationships and constraints.

7 http://www.astm.org/COMMIT/SUBCOMMIT/E3125.htm

8http://www.uml.org

Lantana Consulting Group

Prepared for NIST

ü 2011, all rights reserved
CCR Suitability Analysis

Page 14

May 2011 
There is currently no active development of CCR. Although the standard could therefore be described as "stable" (or, more precisely, unchanging), we believe that true stability results from ongoing testing against the applicable use cases to ensure that a standard continues to meet those defined needs.

Thus, we conclude that the CCR standard is not based on a stable, well-vetted data model, since the standard is not being monitored in case it needs to be updated.

\section{Does the standard have a clear, robust vocabulary binding syntax?}

Although the CCR standard recommends the use of controlled vocabularies, it does not mandate them. Information can be coded using SNOMED CT (Systemized Nomenclature of Medicine, Clinical Terms), ICD-9 CM (International Classification of Diseases), ICD-10, CPT (Current Procedural Terminology), LOINC (Logical Observation Identifies Names and Codes), and RxNorm, or can be described using simple natural-language text strings.

The standard contains the phrase "using the most recent codes at the time CCR is generated" for many of the coding recommendations. This increases the variability among different implementations. Even if the same coding system is used, different implementations may update their codes at different rates. The standard recommends that problems, procedures, products, and agents be coded "to as granular a level as possible", which can also create mismatches through different interpretations of what is, or should, be possible.

In addition, the standard does not completely describe how code systems should be represented. The definition of the XML element $<$ CodingSystem $>$ allows many choices in the way the content can be encoded (e.g., "SNOMED CT", "SCT", or "SNOMEDCT" would each be a valid CCR representation of the SNOMED CT code system). This makes it difficult to validate, compare, or aggregate the data encoded in a CCR.

In conclusion, while CCR does offer some support for the use of vocabularies and code sets, this support is minimal and without sufficient guidance to be maintained and relied upon.

\section{Does the standard support the use of reusable modules, such as templates or data types?}

CCR was designed to meet a single use case and does not support the concept or use of reusable modules. The CCR standard contains XML elements that could be used as "building blocks" for other standards, but this is not defined in the CCR standard. Many of these structures are reused within the CCR standard itself (e.g., the Immunization section reuses structures defined in the Medications section), but the use of these elements in any other standard would have to be considered carefully to avoid unintended consequences.

Thus, the CCR standard does not support the use of reusable modules. Implementers are faced with implementing CCR as a stand-alone interchange format.

\section{Does the standard have a well-defined constraint mechanism?}

\begin{tabular}{|c|c|}
\hline $\begin{array}{l}\text { Lantana Consulting Group } \\
\text { Prepared for NIST }\end{array}$ & $\begin{array}{l}\text { CCR Suitability Analysis } \\
\text { Page } 15\end{array}$ \\
\hline 2011 , all rights reserved & \\
\hline
\end{tabular}


A constraint mechanism restricts the original standard to meet specific business and content needs, such as for specific use cases or geographic locations.

CCR data elements and structures are optional. It does not have a defined mechanism to constrain optionality or create agreement on profiles between users.

The CCR standard does not have a well-defined constraint mechanism.

\section{Does the standard have a well-defined extensibility mechanism?}

The CCR disallows end-user or vendor configurable fields and, thus, all customization and variation is forbidden. This increases interoperability (the given reason for not allowing any customizable fields), but at the cost of excluding related use cases that were not considered when the standard was developed, such as use in international locales.

The CCR standard does not have a well-defined extensibility mechanism and does not provide a method for localization.

\section{Are there unambiguous definitions of what is testable?}

The CCR defines both required and optional items, as well as many recommended items with "either/or" optionality. As an example of the latter, the $<$ Code $>$ element may contain code systems (recommended), simple text strings, or a combination of both.

The CCR states that "Adherence only to the CCR XML schema is necessary, but not sufficient to support interoperability." XML schema validation is a necessary baseline test but it is not a sufficient test mechanism. XML schema can test for the correct spelling of element and attribute names, the presence of required XML elements or attributes, and basic XML well-formedness. XML schema testing is limited for those items that are optional or have alternatives. For example, XML schema validators cannot test that the code system being referenced has the correct name, or that the various values used within an element of type CodedDescriptionType are consistent.

The CCR standard does not have unambiguous definitions of what is testable.

\section{Are there automated test tools and test suites?}

Open Health Data provides an open source ASTM CCR validation tool, available at https:/github.com/openhealthdata/CCR-Validator. It was most recently updated in February 2011 and appears to have two regular developers. It was developed to meet the NIST conformance test procedure for electronic information. ${ }^{9}$ The tool includes validation rules for the use of CCR within the federal regulations for Meaningful Use.

There was a web interface to this tool at http://chit.dyndns.org/ValidationService/for testing purposes, but, when last checked in April 2011, the site was not available.

The CCR standard does have a validation tool.

\section{Are there reference implementations for the standard?}

9 http://healthcare.nist.gov/docs/170.304.f_ElectronicCopyOfHealthInformation v1.0.pdf

\begin{tabular}{|c|c|}
\hline Lantana Consulting Group & CCR Suitability Analysis \\
\hline $\begin{array}{l}\text { Prepared for NIST } \\
\text { ü 2011, all rights reserved }\end{array}$ & Page 16 \\
\hline
\end{tabular}


There are currently no reference implementations of CCR EHR or personal health record (PHR) applications created during the development of the CCR standard.

\section{Has the standard been implemented by a range of vendors?}

CCR is based on a simple XML data model, with an XML schema. Several tools are available that will automatically take XML schemas and produce data objects for software development, thus making the process of exporting a CCR document from an EHR or PHR relatively easy.

According to the e-CareManagement $\operatorname{blog}^{10}$ :

The ASTM CCR standard is more likely to be used in ambulatory settings:

- By organizations that have not yet adopted any standard (e.g., early stage companies)

- To support new business models

- In disruptive applications [...]

- Where the implementers are highly sensitive to incremental costs of IT resources and view the CCR as a "better, faster, cheaper" alternative.

The ONC Certified Health IT Product List ${ }^{11}$ includes over 250 vendors that can create and/or display CCR documents. The commercial implementations of CCR include the following organizations:

- Google Health supports a subset of CCR, detailed at https://code.google.com/apis/health/ccrg reference.html. Google has a number of partners who integrate their solutions with Google Health. They are listed at http://www.google.com/intl/en-US/health/about/profiles.html.

- Microsoft HealthVault can transform HealthVault information items into and out of CCR documents (http://msdn.microsoft.com/en-us/healthvault/dd797577). Microsoft Amalga is an enterprise data aggregation system that can transfer information to a patient's HealthVault record. This is implemented at New York Presbyterian Hospital.

- Allscripts Enterprise EHR (formerly TouchWorks EHR) exports CCR. (http://www.allscripts.com/resources/docs/stimulusPackage/CriteriaforSelectinganEHR.p df)

- eClinicalWorks (http://www.eclinicalworks.com/products-technology.htm) is implemented at Children's National Medical Center of Washington D.C.

- Solventus (http://www.solventus.com)

- NextGen (http://www.nextgen.com/index.asp)

- Allutia from Doctor-Patient Health Records (DHRPHR) (http://allutia.com/)

- Chartware (http://www.chartware.com)

- Good Health Network (http://www.ghnetwork.com/index.html)

- Records For Living (http://www.recordsforliving.com/)

$10 \mathrm{http}: / / \mathrm{e}-\mathrm{caremanagement.com} /$ the-third-rail-in-hitech-implementation-please-dont-make-us-all-speak$\underline{\text { latin/ }}$

11 http://onc-chpl.force.com/ehrcert/chplhome Click on "Inpatient Practice Type" or "Ambulatory Practice Type". Click on "Search by Criteria Met". Scroll down and select "Exchange clinical information and patient summary record". Click on "Search Matching Products". Scroll down to view results.

Lantana Consulting Group

Prepared for NIST

ü 2011, all rights reserved
CCR Suitability Analysis

Page 17
May 2011 
- Digital Clinic from Medico System Inc (http://www.medicosystem.com)

- MedCommons (http://home.medcommons.net/index.html)

- Clinical Portal from Lawson (http://www.lawson.com)

- CareProfile from Availity (http://www.availity.com) is used by many Blue Cross and Blue Shield providers

Google and Microsoft are household names, though not (until recently) big players in health care. Allscripts, on the other hand, is well known in the HIT world. The information that one of their products exports CCR documents, however, came from private communication with a senior developer; it is not listed on the Allscripts web site. This is not exceptional because HIT vendors seldom mention the standards that are implemented in their systems or give any details on the extent to which those standards are used. It is therefore difficult to definitively answer the question of commercial vendor implementation.

The public domain Veterans Health Information Systems and Technology Architecture (VistA) also supports CCR, using the tools for CCR/CCD support to communicate with other EHRs. ${ }^{12}$

There are also a number of open source implementations - many related to VistA:

- VistA-Edge Practice Management System (http://sourceforge.net/projects/vistaedgepms/)

- vxVista (http://www.docstorsys.com/dss-vxOpenSource.html)

- popHealth (http://projectpophealth.org/)

- OpenVista (https://medsphere.org/index.jspa)

- Indivo (http://indivohealth.org/)

- WorldVistA (http://worldvista.org/)

- PatientOS (http://www.patientos.org/)

- ClearHealth (http://www.clear-health.com/)

Two viewing implementations are Android Continuity of Care Record Viewer, ACCReV. A free style sheet for transforming a CCR XML document to HTML (hypertext markup language) is available at http://sourceforge.net/projects/ccr-resources/files/.

A 2008 list of implementations at http://www.ccrstandard.com/ccrstandardimplementationsanddeployments, includes some that no longer exist; however, the CCR standard has been implemented by a range of vendors, small and large, open source and commercial.

\section{Is there documented existence of errors, including estimates of the severity?}

12 "Opensource CCR and CCD support for VistA based systems Project Update (Powerpoint slideshow)" http://groups.google.com/group/ccd-ccr-project/web/CCR-CCD-Update-090219.ppt (Information from https://secure.wikimedia.org/wikipedia/en/wiki/VistA, last accessed March 17, 2011.)

Lantana Consulting Group

Prepared for NIST

ü 2011, all rights reserved
CCR Suitability Analysis

Page 18
May 2011

May 2011 
There are implementation-specific discussion lists for Google Health ${ }^{13}$ and open-source VistA $\mathrm{CCD} / \mathrm{CCR}$ tools ${ }^{14}$, but we were unable to find any general error or discussion lists for CCR implementers available to the public. Email requesting a subscription to the CCR Acceleration Group $^{15}$ went unanswered for a month before being acknowledged.

We do not know of any specific errors in the CCR standard; however, we also do not know if this is because there are no errors, because the implementers have not reported errors, or because reports of any errors are not made public.

\section{Is there a defined and effective process for handling errors?}

We are not members of ASTM. As non-members, we were unable to discover what formal process exists, if any, for notifying ASTM International Technical Committee E31 of any errors in the CCR standard. The ASTM web site gives no obvious process. Private communication indicates that emails to ASTM are routed to technical contacts with no tracking.

The CCR standard does not have a well-described process for handling errors.

\section{Do industry associations endorse the standard?}

The description of CCR (dated 2005) lists a number of organizations as co-leaders with ASTM in the standard's development and adoption. They are the Massachusetts Medical Society, Health Information Management and Systems Society (HIMSS), the American Academy of Family Physicians (AAFP), the American Academy of Pediatrics, the American Medical Association (AMA), the Patient Safety Institute, the American Health Care Association, the National Association for the Support of Long Term Care, the Mobile Healthcare Alliance (MoHCA), the Medical Group Management Association (MGMA), and the American College of Osteopathic Family Physicians (ACOFP).

We were unable to find a current list of industry associations endorsing CCR; however, the fact that the CCR standard is listed as a component of the Meaningful Use Final Rule is an endorsement by the Department of Health and Human Services.

Of the industry associations that endorsed the CCR in 2005, a number of them have references to $\mathrm{CCR}$ on their web sites, indicating continued interest. Chief among these are the Massachusetts Medical Society, HIMSS, the American Academy of Pediatrics, and AAFP (which hosts the "Unofficial FAQs About the ASTM CCR Standard"16 although it appears the FAQs - frequently asked questions - had not been updated for some time when we checked in March 2011).

Thus, the CCR standard was endorsed at its creation by industry associations, some of whom still appear to endorse it, and has since been endorsed by a US Federal department as part of Stage 1 Meaningful Use.

13 https:/groups.google.com/group/googlehealthdevelopers

14 https://groups.google.com/group/ccd-ccr-project

15 http://www.centerforhit.org/online/chit/home/project-ctr/astm/ccraccel.html

16 http://www.centerforhit.org/online/chit/home/project-ctr/astm/unofficialfaq.html

Lantana Consulting Group

Prepared for NIST

CCR Suitability Analysis

Page 19
May 2011

ü 2011, all rights reserved 


\section{Is the standard used in more than one country?}

We found two descriptions of non-US CCR implementations. One is a press release from a Bangkok hospital that implemented CCR to allow US patients to connect to their personal Microsoft HealthVault accounts. ${ }^{17}$

The other is the Singapore General Hospital piloting the use of the CCR standard for continuity in care transfers. The current status of the pilot project is unknown. ${ }^{18}$

We also found a research pilot project undertaken by the Helmholtz Institute in Bavaria, Germany, where they are mapping the CCR to ISO (International Organization for Standardization) EN 13606 for trial in a healthcare network. ${ }^{19}$

There are some university courses in informatics and research institute papers that cite the CCR as a standard to watch, but we were not able to find concrete evidence for actual implementations.

While there is some indication of implementations outside the US, it was not sufficient for us to conclude that the CCR standard is in widespread use in more than one country or endorsed as a local, regional, or national standard in any country outside the US.

\section{Is certification available for developers and architects?}

We have not found any professional certification programs for developers or software architects with expertise in the CCR standard. We followed our standard research procedures, including asking members of the ASTM E31 committee and the ASTM staff liaison for E31 if they knew of any certification programs.

There is a CCR workshop listed on the ASTM web site, but there are no dates listed and the description has not been updated for some time. The workshop can be found only by searching the ASTM web site; it is not in the current course listing.

We conclude that no professional certification program for developers or software architects is available for the CCR standard.

17 http://7thspace.com/headlines/323806/global_leaders team_up to_give_portable_health information to medical travelers.html

18 http://www.ccrstandard.com/ccrstandardimplementationsanddeployments

19 http://www.helmholtz-muenchen.de/en/bymedconnect/home/index.html

Lantana Consulting Group

Prepared for NIST

ü 2011, all rights reserved
CCR Suitability Analysis

Page 20
May 2011 
CCR Suitability Summary

This following matrix summarizes how the suitability criteria can be applied to the CCR standard.

Table 2: CCR Criteria Matrix

\begin{tabular}{|c|c|c|}
\hline Criteria & Results & Notes \\
\hline Is the standard based on a stable, well-vetted data model? & Partial & $\begin{array}{l}\text { The XML schema is a simple data } \\
\text { model. The model is unchanging } \\
\text { rather than stable, as it is not } \\
\text { maintained. }\end{array}$ \\
\hline Does the standard have a clear, robust vocabulary binding syntax? & No & \\
\hline $\begin{array}{l}\text { Does the standard support use of reusable modules, such as } \\
\text { templates or data types? }\end{array}$ & No & \\
\hline Does the standard have a well-defined constraint mechanism? & No & \\
\hline Does the standard have a well-defined extensibility mechanism? & No & \\
\hline Are there unambiguous definitions of what is testable? & No & \\
\hline Are there automated test tools and test suites? & Yes & \\
\hline Are there reference implementations for the standard? & No & \\
\hline Has the standard been implemented by a range of vendors? & Yes & \\
\hline $\begin{array}{l}\text { Is there documented existence of errors, including estimates of } \\
\text { the severity? }\end{array}$ & No & \\
\hline Is there a defined and effective process for handling errors? & No & \\
\hline Do industry associations endorse the standard & Yes & \\
\hline Is the standard used in more than one country? & Partial & $\begin{array}{l}\text { Some pilot projects have been } \\
\text { announced }\end{array}$ \\
\hline Is certification available for developers and architects? & No & \\
\hline
\end{tabular}

\begin{tabular}{|c|c|}
\hline $\begin{array}{l}\text { Lantana Consulting Group } \\
\text { Prepared for NIST }\end{array}$ & $\begin{array}{l}\text { CCR Suitability Analysis } \\
\text { Page } 21\end{array}$ \\
\hline ü 2011, all rights reserved & \\
\hline
\end{tabular}


This section analyzes CCR based on the stricter requirements for Stage 1 Meaningful Use. These criteria "establish the required capabilities and related standards and implementation specifications that certified electronic health record (EHR) technology will need to include ${ }^{\text {,20. }}$. Systems must implement the specifications and functionality in a secure way to satisfy the Final Rule for Stage 1 Meaningful Use.

\section{Meaningful Use: Vocabulary Set}

In the CCR standard, the choice of coding system is optional. This is not the case for Meaningful Use; the coding systems listed in the table below must be used by health plans and healthcare clearinghouses, as well as any healthcare provider who transmits an electronic transaction ${ }^{21}$. The CCR supports most of the Meaningful Use coding systems as well as plain text.

In addition, the CCR standard does not completely describe how code systems should be represented. The XML element $<$ CodingSystem $>$ allows many choices in the way the content can be encoded. For example, the string "SNOMED CT" could be used, or the string "SNMD". The former is recommended, but not required.

Table 3: Meaningful Use Vocabulary Set Supported by CCR

\begin{tabular}{|l|l|l|}
\hline Item & Vocabulary & Supported by CCR? \\
\hline Problem List & ICD9-CM, SNOMED CT & $\begin{array}{l}\text { Yes, with no guidance on how to represent } \\
\text { specific code systems }\end{array}$ \\
\hline Procedures & CPT-4, ICD-9-CM: Procedures, HCPCS & $\begin{array}{l}\text { SNOMED CT, LOINC (preferred); recent } \\
\text { CPT (allowed), with no guidance on how to } \\
\text { represent specific code systems }\end{array}$ \\
\hline Labs & LOINC & $\begin{array}{l}\text { Yes, with no guidance on how to represent } \\
\text { specific code systems }\end{array}$ \\
\hline Medications & RxNorm & $\begin{array}{l}\text { Yes, with no guidance on how to represent } \\
\text { specific code systems }\end{array}$ \\
\hline Immunizations & HL7 CVX - Vaccines Administered & $\begin{array}{l}\text { Yes, with no guidance since you can use } \\
\text { anything you want. You are supposed to } \\
\text { specify the type and then the value. }\end{array}$ \\
\hline RACE/Ethnicity & $\begin{array}{l}\text { The Office of Management and Budget Standards } \\
\text { for Maintaining, Collecting, and Presenting Federal } \\
\text { Data on Race and Ethnicity, Statistical Policy } \\
\text { Directive No. 15, October 30, 1997 }\end{array}$ & $\begin{array}{l}\text { Yes, with no guidance since you can use } \\
\text { anything you want. }\end{array}$ \\
\hline
\end{tabular}

\section{Meaningful Use: Core Set}

The Core Set of functionality is defined as that which every certified EHR system must provide for Meaningful Use. The CCR standard does provide a way to encode much of the data to be

20 http://healthit.hhs.gov/portal/server.pt/community/healthit hhs gov_standards ifr/1195, accessed March 2011

21 Department of Health and Human Services, 45 CFR Parts 160 and 162, Health Insurance Reform: Standards for Electronic Transactions

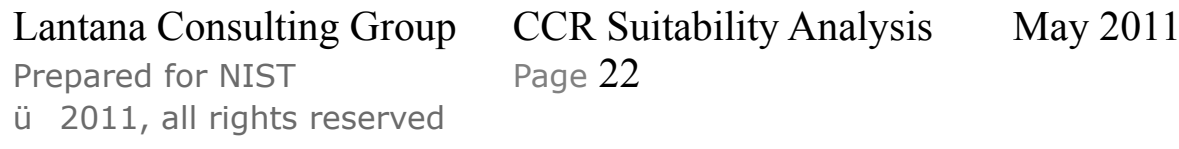


transmitted, though not all. It is important to remember that the scope for CCR is a transitory document for transferring information from one system to another. Some of the Meaningful Use criteria are outside the CCR scope.

Where our notes in the Meaningful Use Core Set table state "can be stored as free-form information", this means that although there is a recommended place - and perhaps a specific XML element - for some of the Meaningful Use information within the CCR document, the content of each of those elements is generic, not specific. The CCR specification has 17 sections at the body level, each designed for a particular type of information. Many of those sections contain generic elements and attributes with names such as $<$ Text $>$ or $<$ Type $>$ or $<$ CodedDescriptionType $>$ that are used to encode the information. Thus, the items required, in particular for demographic information, can be represented in several ways. The standard states, for example, that "5.1.2.7 Social History contains data defining the patient's occupational, personal (for example, lifestyle), social, and environmental history and health risk factors, as well as administrative data (ADT) such as marital status, race, ethnicity, and religious affiliation' ${ }^{, 22}$ but does not specify any more details on how the marital status and risk factors should be represented.

To illustrate this, the following two figures provide alternate methods, each of which could be used to represent a patient's smoking status.

\section{Figure 2: CCR XML smoking status example 1}

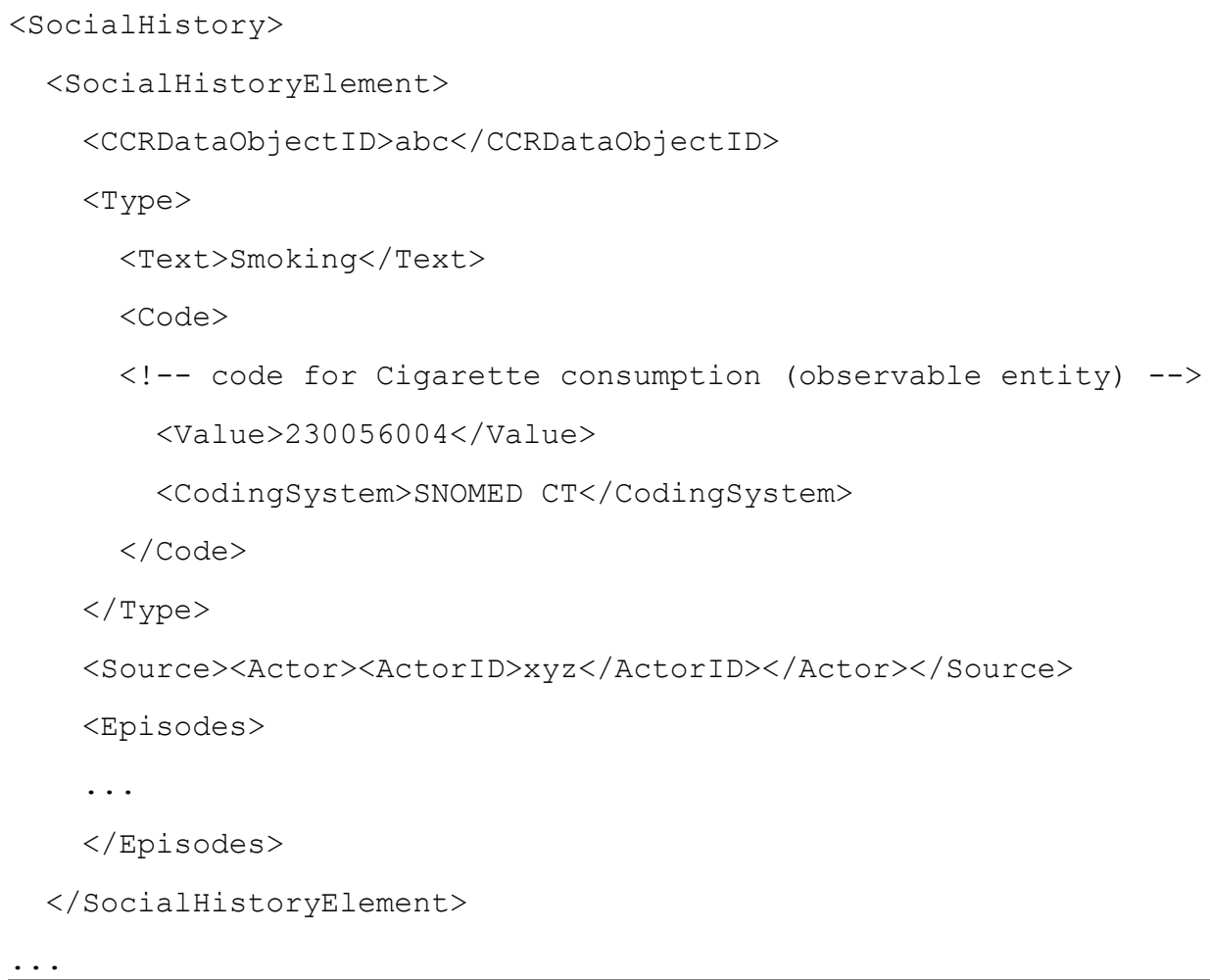

22 ASTM Standard E 2369 - 05 Standard Specification for Continuity of Care Record (CCR)

$\begin{array}{lll}\text { Lantana Consulting Group } & \text { CCR Suitability Analysis } & \text { May } 2011 \\ \text { Prepared for NIST } & \text { Page 23 } \\ \text { ü 2011, all rights reserved } & \end{array}$


Figure 3: CCR XML smoking status example 2

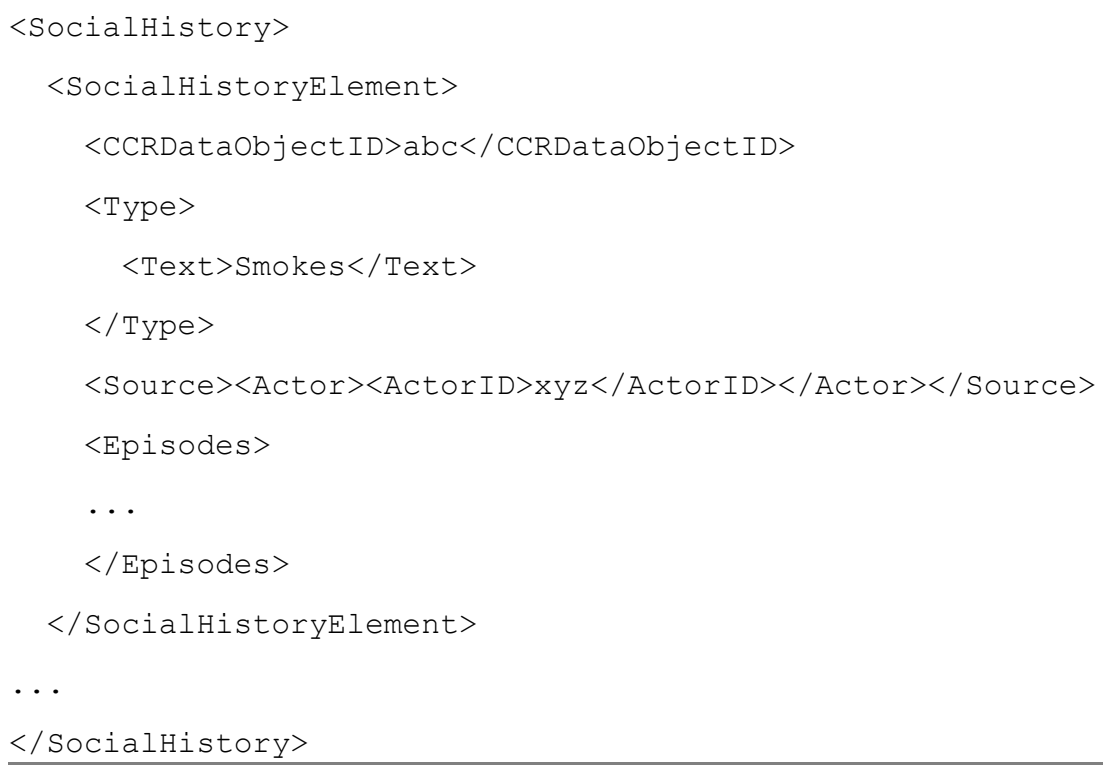

Since there are different ways to represent the same information, combining information from multiple CCR documents is difficult unless the systems creating those documents all make the same coding style choices.

The CCR can satisfy the Stage 1 Meaningful Use requirement of using the Centers for Disease Prevention and Control (CDC) National Health Interview Survey (NHIS) codes for the smoking status $^{23}$ by making use of two features. Information can be encoded with a generic element if there is no specific element available for it, and coding systems other than the recommended ones can be used. The next figure shows a version of the above example that is closer to the intent of Meaningful Use.

Figure 4: Meaningful-Use compliant CCR XML smoking status example

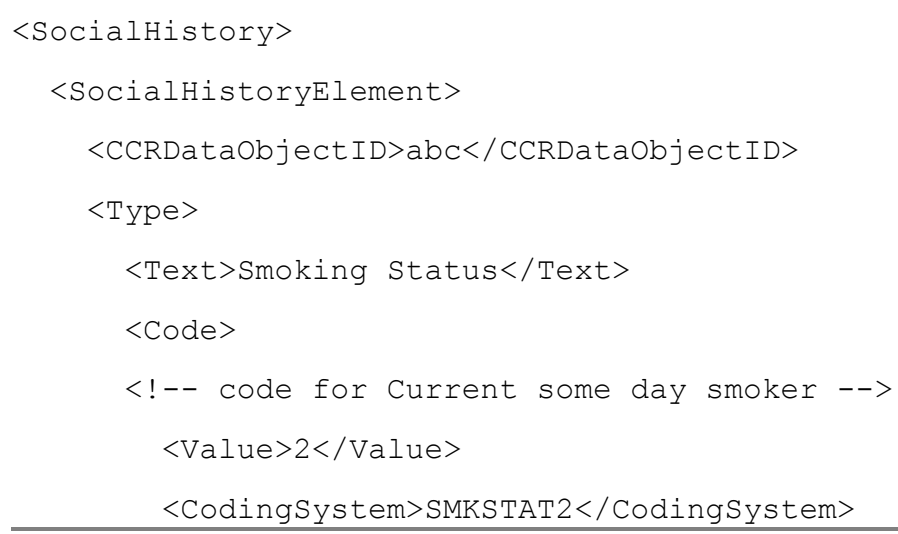

23 Available at http://www.cdc.gov/nchs/nhis/tobacco/tobacco recodes.htm

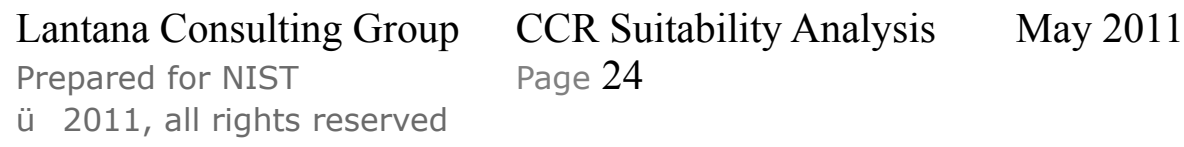




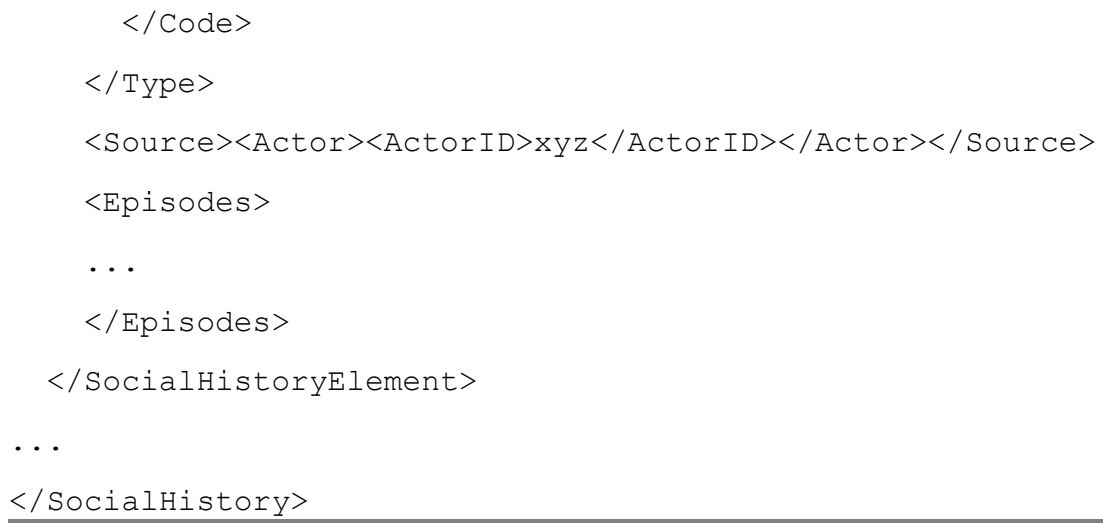

Thus, CCR's method of encoding much of the information in a relatively free-form manner makes it difficult to aggregate the information and lowers the interoperability between systems (the implementers of the systems need to agree on details that are not specified in the standard), but does allow for unforeseen use cases.

In conclusion, the CCR supports the Meaningful Use data set, though not necessarily in a form that makes aggregation of the data easy. In the table below, we list the Core Set criteria and whether they are supportable by the CCR. If CCR were profiled so that the many choices and options were reduced to a set that matches the Meaningful Use requirements, it would have a wider range of applicability.

Table 4: Meaningful Use Core Set Supportable by CCR

\begin{tabular}{|c|c|}
\hline Core Set Criteria & Supportable by CCR? \\
\hline $\begin{array}{l}\text { Record patient demographics (preferred language, insurance type, } \\
\text { gender, race and ethnicity, date of birth, and date and cause of death } \\
\text { in the event of mortality). }\end{array}$ & $\begin{array}{l}\text { Except for date and cause of death, which have } \\
\text { specific elements, all can be stored as free-form } \\
\text { information within }<\text { SocialHistoryElement }>\text { elements } \\
\text { in the }<\text { SocialHistory }>\text { element. }\end{array}$ \\
\hline $\begin{array}{l}\text { Record vital signs and chart changes (height, weight, and blood } \\
\text { pressure and calculate and display body mass index (BMI) for ages } 2 \\
\text { and over; plot and display growth charts for children 2-20 years, } \\
\text { including BMI). }\end{array}$ & $\begin{array}{l}\text { All except the growth charts can be stored as free- } \\
\text { form information within }<\text { Results }>\text { elements in the } \\
\text { kVitalSigns }>\text { element. The growth charts could be put } \\
\text { in as images, but there is no specific support for them. }\end{array}$ \\
\hline $\begin{array}{l}\text { Maintain up-to-date problem list of current and active diagnoses. } \\
\text { Maintain an active medication list. } \\
\text { Maintain an active medication allergy list. } \\
\text { Record smoking status for patients } 13 \text { and older. }\end{array}$ & $\begin{array}{l}\text { Diagnoses: Yes, in the }<\text { Problem }>\text { element. } \\
\text { Medications: Yes, in the }<\text { Medications }>\text { element, } \\
\text { including the allergies. } \\
\text { Smoking status: Yes, in the }<\text { SocialHistory }>\text { element. }\end{array}$ \\
\hline $\begin{array}{l}\text { Provide patients with clinical summaries for each office visit: } \\
\text { clinical summary is an after-visit summary that provides a patient } \\
\text { with relevant and actionable information and instructions containing, } \\
\text { but not limited to, the patient name, provider's office contact } \\
\text { information, date and location of visit, an updated medication list } \\
\text { and summary of current medications, updated vitals, reason(s) for } \\
\text { visit, procedures and other instructions based on clinical discussions } \\
\text { that took place during the office visit, any updates to a problem list, } \\
\text { immunizations or medications administered during visit, summary of } \\
\text { topics covered/considered during visit, time and location of next } \\
\text { appointment/testing if scheduled, or a recommended appointment } \\
\text { time if not scheduled, list of other appointments and testing patient } \\
\text { needs to schedule with contact information, recommended patient } \\
\text { decision aids, laboratory and other diagnostic test orders, } \\
\text { test/laboratory results (if received before } 24 \text { hours after visit), and }\end{array}$ & Yes. \\
\hline
\end{tabular}

\begin{tabular}{|c|c|}
\hline Lantana Consulting Group & CCR Suitability Analysis \\
\hline ü 2011, all rights reserved & \\
\hline
\end{tabular}




\begin{tabular}{|c|c|}
\hline symptoms. & \\
\hline $\begin{array}{l}\text { Provide patients with an electronic copy of their discharge } \\
\text { instructions at time of discharge from the hospital, upon request. }\end{array}$ & $\begin{array}{l}\text { No. "Since the CCR is a core data set of selected, } \\
\text { relevant information, it is not a discharge summary" } 24\end{array}$ \\
\hline $\begin{array}{l}\text { Provide patients with an electronic copy of their health information } \\
\text { (including diagnostics test results, problem list, medication lists, } \\
\text { medication allergies) upon request. }\end{array}$ & Yes. \\
\hline $\begin{array}{l}\text { Generate and transmit permissible prescriptions electronically (does } \\
\text { not apply to hospitals). }\end{array}$ & Yes. \\
\hline Provide Computerized Provider Order Entry for Medication Orders. & No. \\
\hline $\begin{array}{l}\text { Implement drug-drug and drug-allergy interaction checks. } \\
\text { Functionality must be enabled for these checks for the entire } \\
\text { reporting period. }\end{array}$ & No. It has the drug data, but not the decision support. \\
\hline $\begin{array}{l}\text { Implement capability to electronically exchange key clinical } \\
\text { information among providers and patient-authorized entities. Must } \\
\text { perform at least one test of the EHR's capacity to electronically } \\
\text { exchange information. }\end{array}$ & Yes. \\
\hline $\begin{array}{l}\text { Implement one clinical decision support rule and track compliance } \\
\text { with that rule. One rule must be implemented. }\end{array}$ & No. \\
\hline $\begin{array}{l}\text { Protect electronic health information created or maintained by the } \\
\text { certified EHR technology through the implementation of appropriate } \\
\text { technical capabilities. Conduct or review a security risk analysis in } \\
\text { accordance with the requirements under } 45 \text { CFR } 164.308(a)(1) \text { and } \\
\text { implement security updates as necessary and correct identified } \\
\text { security deficiencies as part of its risk management process. }\end{array}$ & $\begin{array}{l}\text { Yes, where relevant. The CCR specification includes } \\
\text { security and privacy considerations as requirements, } \\
\text { but does not discuss what would be entailed in a } \\
\text { security risk analysis. }\end{array}$ \\
\hline $\begin{array}{l}\text { Report clinical quality measures to CMS or states. } \\
\text { For 2011, provide aggregate numerator and denominator through } \\
\text { attestation. } \\
\text { For } 2012 \text {, electronically submit measures. }\end{array}$ & $\begin{array}{l}\text { Some }{ }^{25} \text {. Pophealth imports CCR documents and then } \\
\text { uses that data to compute the numerator and } \\
\text { denominator. Some quality measures require data that } \\
\text { isn't in the CCR ( e.g., discharge medication). }\end{array}$ \\
\hline
\end{tabular}

\section{Meaningful Use: Menu Set}

The Meaningful Use Menu Set lists additional criteria for certified EHR systems. These systems must provide a specified percentage of the functionality listed in the Menu Set (see the Meaningful Use Menu Set Supported by CCR Table below). The current expectation is that Stage 2 Meaningful Use will require certified systems to have all of the items in the Menu Set.

For many of these items, the EHR system could use data encoded in the CCR as input to the required functionality, but in many cases that use is not directly supported by the standard. The CCR can encode information for six of the twelve Menu Set items, with some caveats. The recording physician must be aware of the proposed use of the information to ensure that all relevant information is included. The relevant information can be coded within a CCR document in more than one way, so that the CCR must be profiled to support data aggregation and secondary use.

Table 5: Meaningful Use Menu Set Supportable by CCR

24 ASTM Standard E 2369 - 05 Standard Specification for Continuity of Care Record (CCR), page 1 25 For an example, see http://projectpophealth.org/faq.html - standards

$\begin{array}{ll}\text { Lantana Consulting Group } & \begin{array}{l}\text { CCR Suitability Analysis } \\ \text { Page } 26\end{array} \\ \begin{array}{l}\text { Prepared for NIST } \\ \text { ü 2011, all rights reserved }\end{array} & \end{array}$


Implement drug formulary checks. Drug formulary check system No.

must be implemented and access at least one internal or external drug formulary during the reporting period.

\begin{tabular}{|l|l}
\hline Incorporate clinical laboratory test results into EHRs as & Yes.
\end{tabular}

structured data.

Generate lists of patients by specific conditions for use for quality improvement, reduction of disparities, research or outreach.

The CCR could supply data to an EHR for this calculation if it were appropriately profiled.

\begin{tabular}{|l|l}
\hline Use EHR technology to identify patient-specific education & No.
\end{tabular} resources and provide those to the patient as appropriate.

Perform Medication reconciliation between care settings.

Yes. The definitions used for medication reconciliation are not precise, so the CCR can supply data. A profiled CCR would, of course, be better.

Provide summary of care record for patients referred or transitioned to another provider or setting. Transition of care

means the movement of a patient from one setting of care (hospital, ambulatory primary care practice, ambulatory, specialty care practice, long-term care, home health, rehabilitation facility) to another.

Submit electronic immunization data to immunization registries or immunization information systems.

Submit electronic syndromic surveillance data to public health agencies.

Yes (this was the original intent for the CCR). For hospitals, record advanced directives for patients 65 years or Yes. older.

For hospitals, submit electronic data on reportable laboratory results to public health agencies. \begin{tabular}{|l|l}
\hline For professionals, send reminders to patients (per patient & No.
\end{tabular} preference) for preventative and follow-up care.

For professionals, provide patients with an electronic copy of their health information (including diagnostics test results,

problem list, medication lists, medication allergies) upon request.

Not applicable, since MU requires HL7 V2 messaging. Not applicable, since MU requires HL7 V2 messaging.

Not applicable, since MU requires HL7 V2 messaging Yes.

$\begin{array}{ll}\text { Lantana Consulting Group } & \begin{array}{l}\text { CCR Suitability Analysis } \\ \text { Page } 27\end{array} \\ \begin{array}{ll}\text { Prepared for NIST } & \text { May } 2011 \\ \text { ü 2011, all rights reserved } & \end{array}\end{array}$




\section{Conclusions}

The CCR standard is well known in HIT. It was designed to transfer relevant records when a patient moves from one provider to another. CCR is a relatively simple standard to understand. The number of implementations shows that it is considered suitable for HIT use. It is generally considered sufficient for ambulatory settings ${ }^{26}$ and for giving patients access to their health information $^{27}$.

We found, however, that the CCR standard does not satisfy many of our suitability requirements, and some that it does satisfy come with caveats. There are indeed implementations by a range of large and small vendors, and open-source implementations are also available. Many industry organizations endorsed CCR in 2005 and contributed to its development, but the ASTM stopped seeking official sponsors after the standard was published ${ }^{28}$. The validation suite, although open source and regularly updated, appears to have only two regular contributors. We could find no error lists or process for reporting errors available to non-members. In private communications, E31 members said that emails to ASTM with questions are typically passed on to technical contacts and not tracked. There is a CCR Acceleration Group ${ }^{29}$ that we subscribed to, but there was no email traffic in two months, making it difficult to judge how active the group is.

The CCR satisfies some of the Meaningful Use criteria, again with caveats. In many cases CCRrecommended code systems would satisfy the Stage 1 Meaningful Use criteria, but CCR also allows plain text, which falls short of the Meaningful Use standards. In other cases, such as for demographics, there are no dedicated elements or attributes in the CCR XML schema. Thus, there could be confusion over how to code those items defined by Meaningful Use, leading to a decrease in interoperability at best, and the potential of improper processing of important information. The lack of a well-defined constraint mechanism in the CCR becomes apparent here, since there is no defined process for creating a profile of the CCR for Meaningful Use.

CCR was designed for one purpose and is specific to that use case. It is not extensible, so cannot easily satisfy variations of that use case or be localized where constraints or extensions are required. As CCR is a stand-alone standard, implementers of CCR or CCR data objects cannot apply that experience to implementing other potentially related clinical-care document formats. The concepts within CCR are useful, however, and map to many of the Stage 1 Meaningful Use criteria. The concepts underlying CCR (which are the same as those in CCD) are important as illustrated by its use in PHR systems. The issues and problems documented in this analysis fall into six categories, for which specific actions are defined in the related "CCR Action Plan"30.

- Refine the standard to add constraint and extensibility mechanisms, develop templates, add a vocabulary binding syntax, and define testability.

26 http://www.hl7standards.com/blog/2010/03/10/ccd-and-ccr-the-discussion-continues/

27 http://jamia.bmj.com/content/18/2/118.full.html

28 Dan Smith, ASTM Staff Liaison for Committee E31, private communication

29 http://www.centerforhit.org/online/chit/home/project-ctr/astm/ccraccel.html

30 Lantana Consulting Group. CCR Action Plan, June 2011. Related document prepared for NIST.

Lantana Consulting Group

Prepared for NIST

ü 2011, all rights reserved
CCR Suitability Analysis

Page 28

May 2011 
- Profile the standard to define elements and vocabularies that are needed for Meaningful Use.

- Create more testing tools and a reference implementation to improve testing and validation.

- Improve the process for error handling.

- Create a certification program for developers and architects.

- Create additional documentation.

If problems these are resolved, CCR could be considered for implementation in clinical healthcare systems to support Meaningful Use.

Lantana Consulting Group

Prepared for NIST

ü 2011, all rights reserved
CCR Suitability Analysis

Page 29 
References

- An Analysis of the Final Standards Rule.
http://geekdoctor.blogspot.com/2010/07/analysis-of-final-standards-rule.html
- ASTM Standard E2369 - 05e1. Standard Specification for Continuity of Care Record
(CCR). DOI: 10.1520/E2369-05E01. 2005. $\underline{\text { http://www.astm.org/Standards/E2369.htm }}$
- Department of Health and Human Services, 45 CFR Parts 160 and 162, Health Insurance

- An Analysis of the Final Standards Rule.
http://geekdoctor.blogspot.com/2010/07/analysis-of-final-standards-rule.html
- ASTM Standard E2369 - 05e1. Standard Specification for Continuity of Care Record
(CCR). DOI: 10.1520/E2369-05E01. 2005. http://www.astm.org/Standards/E2369.htm
- Department of Health and Human Services, 45 CFR Parts 160 and 162, Health Insurance

- An Analysis of the Final Standards Rule.
http://geekdoctor.blogspot.com/2010/07/analysis-of-final-standards-rule.html
- ASTM Standard E2369 - 05e1. Standard Specification for Continuity of Care Record
(CCR). DOI: 10.1520/E2369-05E01. 2005. http://www.astm.org/Standards/E2369.htm
- Department of Health and Human Services, 45 CFR Parts 160 and 162, Health Insurance

- An Analysis of the Final Standards Rule.
http://geekdoctor.blogspot.com/2010/07/analysis-of-final-standards-rule.html
- ASTM Standard E2369 - 05e1. Standard Specification for Continuity of Care Record
(CCR). DOI: 10.1520/E2369-05E01. 2005. http://www.astm.org/Standards/E2369.htm
- Department of Health and Human Services, 45 CFR Parts 160 and 162, Health Insurance

- An Analysis of the Final Standards Rule.
http://geekdoctor.blogspot.com/2010/07/analysis-of-final-standards-rule.html
- ASTM Standard E2369 - 05e1. Standard Specification for Continuity of Care Record
(CCR). DOI: 10.1520/E2369-05E01. 2005. http://www.astm.org/Standards/E2369.htm
- Department of Health and Human Services, 45 CFR Parts 160 and 162, Health Insurance Reform: Standards for Electronic Transactions

- Department of Health and Human Services. Health Information Technology: Initial Set of Standards, Implementation Specifications, and Certification Criteria for Electronic Health Record Technology; Final Rule, 45 CFR Part 170. http://edocket.access.gpo.gov/2010/pdf/2010-17210.pdf

- Department of Health and Human Services. Medicare and Medicaid Programs; Electronic Health Record Incentive Program; Final rule - Stage 1 Meaningful Use Objectives, 42 CFR Parts 412, 413, 422 et al. http://edocket.access.gpo.gov/2010/pdf/2010-17207.pdf

- Department of Health and Human Services. Standards \& Certification Criteria Final Rule (web site). http://healthit.hhs.gov/portal/server.pt/community/healthit_hhs_gov_standards_ifr/1195

- Extensible Markup Language, www.w3.org/XML.

- HL7 Health Standards Blog: CCD and CCR - the Discussion Continues. http://www.h17standards.com/blog/2010/03/10/ccd-and-ccr-the-discussion-continues/

- Kuraitis, V and Waldren, S. e-CareManagement Blog. The Third Rail in HITECH Implementation: "Please Don't Make Us All Speak Latin", posted September 2009. http://e-caremanagement.com/the-third-rail-in-hitech-implementation-please-dont-makeus-all-speak-latin/

- Lantana Consulting Group. Healthcare Information Technology Standards: General Suitability Analysis, May 2011. Related document prepared for NIST.

- Lantana Consulting Group. CCR Action Plan, June 2011. Related document prepared for NIST.

- $\quad$ LOINC $^{\circledR}$ : Logical Observation Identifiers Names and Codes, Regenstrief Institute. http://www.regenstrief.org/loinc

- National Institue of Standards and Technology. Test Procedure for $\$ 170.304(f)$ Electronic Copy of Health Information. Version 1.0, August 13, 2010. http://healthcare.nist.gov/docs/170.304.f_ElectronicCopyOfHealthInformation_v1.0.pdf

- Office of the National Coordinator (ONC) for Health Information Technology. Certified Health IT Product List. http://onc-chpl.force.com/ehrcert/ehrproductcriteriasearch

- Peters, RM, Jr., Kibbe, DC, Sullivan, T, Tessier, C, and Zuckerman, A. A Rebuttal to Wes Rishel's Gartner Report 'Two Versions of Continuity of Care Record Offer Different Approaches to Interoperability' - and a Proposal for Rapid Progress on Interoperability.” April 6, 2005. http://www.centerforhit.org/online/etc/medialib/chit/documents/projctr/rebuttal-wes-rishel-rep.Par.0001.File.tmp/chit_CCRCDARebuttal.pdf

- popHealth Glossary.http://projectpophealth.org/glossary.html

Lantana Consulting Group

Prepared for NIST

ü 2011, all rights reserved
CCR Suitability Analysis

Page 30

May 2011

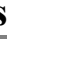


- SNOMED CT $^{\circledR}$ : SNOMED Clinical Terms SNOMED International Organization. http://www.ihtsdo.org/

- The Clinical Document Architecture and the Continuity of Care Record: A Critical Analysis: http://www.ncbi.nlm.nih.gov/pmc/articles/PMC1513652/

Lantana Consulting Group

Prepared for NIST

ü 2011, all rights reserved
CCR Suitability Analysis May 2011 Page 31 


\section{Acronyms and Abbreviations}

AAFP American Academy of Family Physicians

ACOFPAmerican College of Osteopathic Family Physicians

ADT administrative data

AMA American Medical Association

ASTM originally called the American Society for Testing and Materials

BMI Body Mass Index

CCD Continuity of Care Document

CCR Continuity of Care Record

CDA Clinical Document Architecture

CDC Center for Disease Prevention and Control (CDC)

CFR Code of Federal Regulations

CPT Current Procedural Terminology

DHRPHR Doctor-Patient Health Records

DOM Document Object Model

EHR Electronic Health Record

FAQs frequently asked questions

H\&P History and Physical

HHS Department of Health and Human Services

HIMSS Health Information Management and Systems Society

HIT Healthcare Information Technology

HL7 Health Level Seven

HTML hypertext markup language

ICD International Classification of Diseases

ISO International Organization for Standardization

LOINC Logical Observation Identifiers Names and Codes

MGMAMedical Group Management Association

MoHCA Mobile Healthcare Alliance

Lantana Consulting Group

Prepared for NIST

ü 2011, all rights reserved
CCR Suitability Analysis May 2011

Page 32 
MU Meaningful Use

NHIS National Health Interview Survey

NIST National Institute of Standards and Technology

OCL Object Constraint Language

ONC Office of the National Coordinator

PDF portable document format

PHR Personal Health Record

QRDA Quality Reporting Document Architecture

SDO standards developing organization

SNOMED CT Systematized Nomenclature of Medicine, Clinical Terms

UML Unified Modeling Language

VistA Veterans Health Information Systems and Technology Architecture

W3C World Wide Web Consortium

XML Extensible Markup Language

Lantana Consulting Group

Prepared for NIST

ü 2011, all rights reserved
CCR Suitability Analysis May 2011

\section{Page 33}

